\title{
Haematological, oxidative stress and electrolyte alterations in puppies with canine parvoviral enteritis
}

\author{
C.S. Ukwueze ${ }^{1 *}$, E.S. Akpan ${ }^{1}$, R.C. Ezeokonkwo ${ }^{2}$, C.I. Nwosuh ${ }^{3}$ and B.M. Anene ${ }^{4}$ \\ ${ }^{1}$ Department of Veterinary Medicine, Michael Okpara University of Agriculture, Umudike, ${ }^{2}$ Department of Veterinary \\ Parasitology, University of Nigeria, Nsukka, ${ }^{3}$ Research Directorate, National Veterinary Research Institute, Vom, \\ ${ }^{4}$ Department of Veterinary Medicine, University of Nigeria, Nsukka, Nigeria \\ *Correspondence: chynet2006@yahoo.com, +2348030793359
}

(Received March 21, 2019; Accepted July 6, 2019)

\begin{abstract}
Haematological changes, oxidative stress markers and electrolyte alterations were evaluated in puppies infected with canine parvovirus type 2 (CPV-2) that were presented to veterinary hospitals and clinics in South Eastern, Nigeria. Fifty-one dogs were used for the study and they were assigned into three groups. Group I consist of 21 diarrhoeic dogs naturally infected with canine parvovirus, groups II, were 15 diarrhoeic dogs uninfected with canine parvovirus and group III, were 15 apparently healthy dogs which served as the control. Immunochromatographic (IC) test was used to screen the dogs for canine parvovirus type 2 infections. The mean red blood cell (RBC) counts, packed cell volume (PCV) and haemoglobin (HB) concentrations were significantly lower in the diarrhoeic infected than diarrhoeic non-infected and the control groups. The mean catalase (CAT) of diarrhoeic non-infected group was significantly lower than diarrhoeic infected group and the control. The mean malondialdehyde (MDA) of both diarrhoeic infected and diarrhoeic non-infected groups were significantly higher than the control. The mean serum sodium $\left(\mathrm{Na}^{+}\right)$level of the diarrhoeic non infected group was significantly lower than the diarrhoeic infected group. The mean serum potassium $\left(\mathrm{K}^{+}\right)$level was significantly lower both in diarrhoeic infected and diarrhoeic noninfected groups compared to the control groups. It was therefore concluded that the levels of oxidative stress and electrolyte alterations may not be affected by the origin or aetiology of a disease (CPV-2), but on the severity of the infection.
\end{abstract}

Keywords: CPV-2, Haematology, Oxidative stress, Electrolytes alterations, Dogs

Available online at http://www.vetmedmosul.com, (C) 2020, College of Veterinary Medicine, University of Mosul.

This is an open access article under the CC BY 4.0 license (http://creativecommons.org/licenses/by/4.0/).

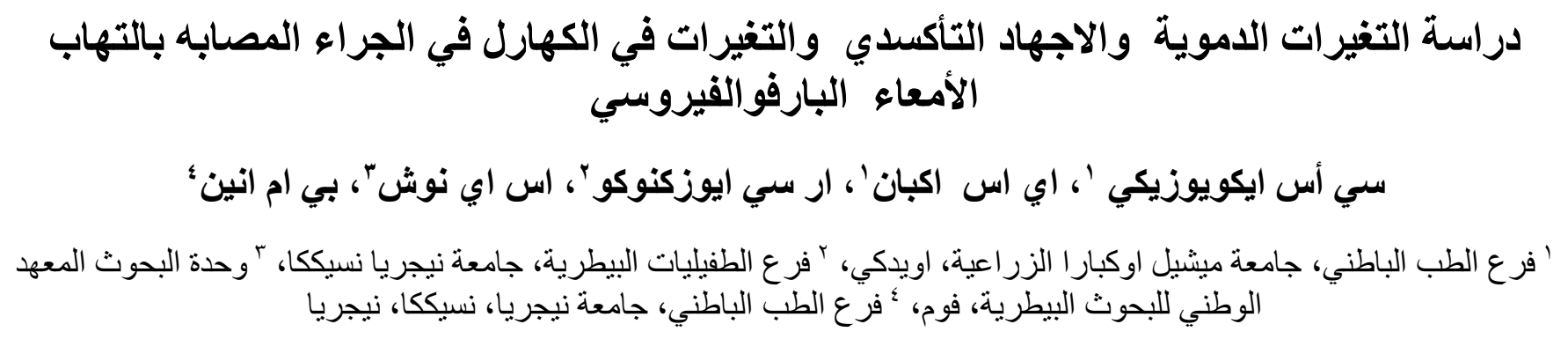

هدف البحث اللى تقييم التغير ات الدموية، علامات الإجهاد التأكسدي و التغيرات في الاكتروو لايت في الكلاب المصابة بفيروس بارفوف

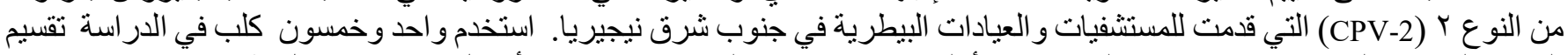

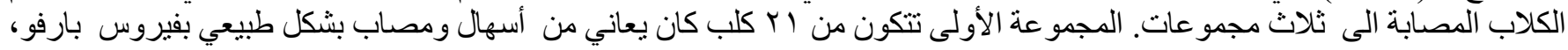

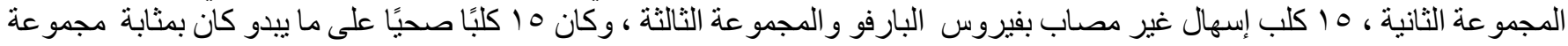

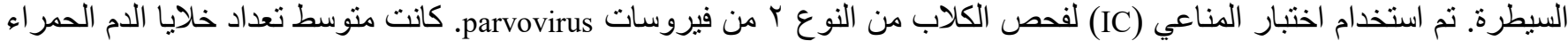

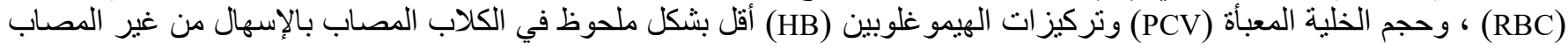




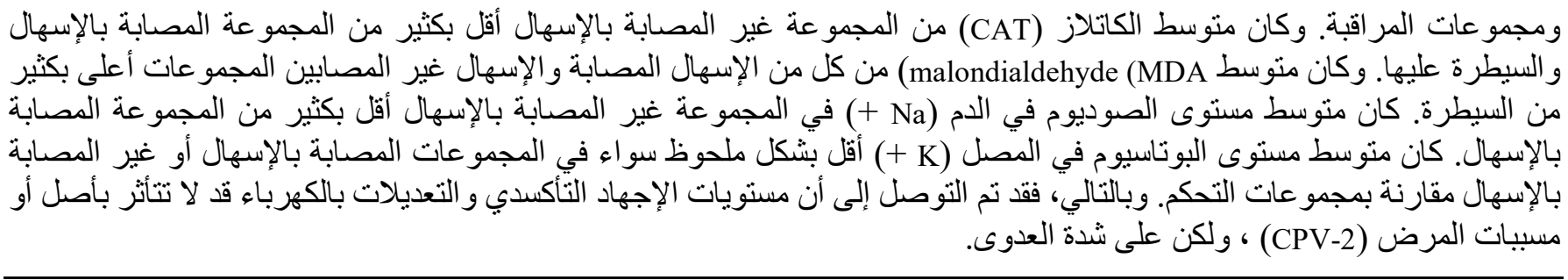

\section{Introduction}

For the past three decades, canine parvovirus infection has been a major disease of dogs characterized majorly by gastroenteritis $(1,2)$. The infection has been reported in many parts of the world and it continues to emerge as a serious threat to the canine population despite the availability of vaccine (1). Acute parvoviral enteritis has been seen in dogs of all breeds, age and sex, but puppies between 6 weeks and 6 months appear to be more susceptible $(3,4)$. Enteritis and myocarditis are the two major disease forms associated with CPV-2 infection, though the myocarditis form is now extremely rare clinical manifestation because of vaccination, unless infection occurred in utero or in puppies born from unvaccinated bitches (5-7). Acute enteritis however, is the most common manifestation of the disease and more fatal form $(8,9)$. Clinical manifestations of the disease are nonspecific and may include anorexia, depression, lethargy and fever. As the course of disease progresses, typical clinical signs will include vomiting and foul-smelling diarrhoea that can range from mucoid to purely haemorrhagic (10-12). Due to large fluid and protein losses through the gastrointestinal tract, dehydration and hypovolaemic shock often develop rapidly. Marked abdominal pain is a feature of CPV-2 enteritis and can be due to either acute gastroenteritis or intestinal intussusceptions $(7,12)$. Damage to the intestinal tract increases the risk of bacterial translocation and subsequent septicaemia, which may lead to the development of a systemic inflammatory response that can progress to septic shock and ultimately death $(8,13,14)$. Oxidative stress and inflammatory reactions have been suggested to play major roles in the pathogenesis of many diseases and inflammatory conditions. Reactive oxygen species (ROS) is one of the earliest cellular responses following successful pathogen recognition and are produced as a defence mechanism of the body and other cells during immune activation (15). Evidence of systemic oxidative stress is manifested as increased lipid peroxidation (16), and depletion of the antioxidant status of infected animals by increased production of free radicals (17).

This study, therefore, highlights the haematological changes, oxidative stress and electrolyte alterations associated with CPV-2 infections of dogs presented to veterinary hospitals and clinics in South Eastern, Nigeria.

\section{Materials and methods}

\section{Experimental animals}

A total of fifty-one puppies between the ages of 1-12 months were used for the study. The diarrhoeic dogs used were randomly selected from dogs presented to various veterinary hospitals and clinics in South Eastern, Nigeria. The patient profile and the history of each dog including the feeding, housing and other management practices were carefully evaluated before the commencement of the study. The dogs used for the study were mainly fed with homemade diet. All the dogs were screened for CPV-2 using Immunochromatographic (IC) test as described by (18) and were grouped into three. Group I consist of 21 diarrhoeic dogs naturally infected with canine parvovirus, groups II, were 15 diarrhoeic dogs uninfected with canine parvovirus and group III, were 15 apparently healthy dogs which served as the control.

\section{Blood and serum sample collection}

Blood samples for this study were collected from the cephalic vein of the dogs. $2 \mathrm{ml}$ of blood for haematology was collected into vacutainer tubes containing ethylene diamine tetra acetic acid (EDTA) as anticoagulant. The sample bottles were rocked gently to mix the blood with the EDTA to prevent clotting. For biochemical analysis $5 \mathrm{ml}$ of blood was collected from the cephalic vein of each dog into a vacutainer tube without anticoagulant and the tube was left undisturbed for 30 minutes to allow clotting. The clotted blood was then centrifuged for 2 minutes at 30,000 revolutions per minute using a microhematocrit centrifuge. The serum supernatant was immediately aspirated into labelled sample bottles and refrigerated until use.

\section{Determination of haematological parameters}

The haematological parameter, red blood cell count (RBC count), packed cell volume (PCV), haemoglobin concentration (HB), white blood cell (WBC), mean corpuscular volume (MCV), mean corpuscular haemoglobin $(\mathrm{MCH})$, mean corpuscular haemoglobin concentration (MCHC), were analysed using an automated haematology analyser (model 2800 BC produced by Mindray Company, India) following standard procedures outlined by the producer. 


\section{Determination of oxidative stress parameters}

Glutathione peroxidase (GPx) was determined according to the method described by Moron et al (19). The superoxide dismutase (SOD) was determined as described by Marklund and Marklund (20). The catalase (CAT) activity was determined by the method described by Sinha (21). Malondialdehyde (MDA) was determined spectrophotometrically by measuring the level of the lipid peroxidation product as described by Wallin et al (22).

\section{Electrolytes}

The serum levels of sodium, potassium, chloride and bicarbonate were determined using a commercial kit (TECO Diagnostics, USA), following the manufacturer's instructions.

\section{Statistical analysis}

Data obtained were expressed as mean \pm standard error of the mean and were analysed using one-way analysis of variance with SPSS version 20 software package. The level of significance was accepted at $\mathrm{P}<0.05$.

\section{Results}

\section{Haematology}

The mean RBC counts, PCV and HB concentrations were significantly lower in the diarrhoeic infected than diarrhoeic non-infected and the control groups. The mean WBC counts of the diarrhoeic infected group did not show any significant difference with the diarrheic non-infected, but were significantly higher than the control. The mean $\mathrm{MCH}$ and MCHC were significantly lower in the diarrhoeic noninfected group than the diarrhoeic infected group, but did not differ significantly with the control (Table 1).

\section{Oxidative stress parameters}

The mean SOD of the diarrhoeic infected group did not show any significant difference with the diarrhoeic noninfected, but differed significantly from the control. The mean CAT of diarrhoeic non-infected group was significantly lower than diarrhoeic infected group and the control. The mean MDA of both diarrhoeic infected and diarrhoeic non-infected groups were significantly higher than the control, but the diarrhoeic infected group was significantly lower than diarrheic non-infected group (Table 2).

\section{Electrolytes}

The mean $\mathrm{Na}^{+}$of the diarrhoeic non infected group was significantly lower than the diarrhoeic infected group, but did not differ significantly with the control. The mean $\mathrm{K}^{+}$and $\mathrm{HCO}_{3}{ }^{-}$of the diarrhoeic infected did not differ significantly from diarrhoeic non-infected, but $\mathrm{K}^{+}$was significantly lower than the control (Table 3).

Table 1: The mean haematological changes of CPV-2 diarrhoeic infected and diarrhoeic non-infected puppies

\begin{tabular}{lccc}
\hline Parameters & Control (Healthy Dogs) $\mathrm{n}=15$ & Diarrhoeic $($ Infected) $\mathrm{n}=21$ & Diarrhoeic (Non-infected) $\mathrm{n}=15$ \\
\hline RBC $\left(\times 10^{12} / \mathrm{L}\right)$ & $6.1 \pm 0.10^{* *}$ & $5.0 \pm 0.11^{*}$ & $7.9 \pm 0.15^{* * *}$ \\
PCV $(\%)$ & $40.7 \pm 0.70^{* *}$ & $32.8 \pm 0.73^{*}$ & $52.3 \pm 1.36^{* * *}$ \\
Hb $(\mathrm{g} / \mathrm{dL})$ & $11.8 \pm 0.21^{* *}$ & $9.9 \pm 0.29^{*}$ & $14.2 \pm 0.10^{* * *}$ \\
WBC $\left(\times 10^{9} / \mathrm{L}\right)$ & $9.6 \pm 0.41^{* *}$ & $16.5 \pm 0.90^{*}$ & $16.3 \pm 0.79^{*}$ \\
Platelets $\left(\times 10^{9} / \mathrm{L}\right)$ & $103.7 \pm 2.26$ & $100.7 \pm 1.96$ & $94.5 \pm 3.84$ \\
MCV $(f 1)$ & $66.3 \pm 0.52$ & $65.5 \pm 1.68$ & $66.2 \pm 1.28$ \\
MCH $(p g)$ & $19.3 \pm 0.42$ & $19.8 \pm 0.40$ & $17.9 \pm 0.28^{* *}$ \\
MCHC $(\mathrm{g} / \mathrm{l})$ & $290.8 \pm 6.77$ & $305.1 \pm 9.08$ & $271.9 \pm 6.60^{* *}$ \\
\hline
\end{tabular}

Mean \pm SEM. Means marked * are significantly different from control group while those marked $* *$ are significantly different from diarrhoeic (infected) group.

Table 2: The mean oxidative stress levels of CPV-2 diarrhoeic infected and diarrhoeic non-infected puppies

\begin{tabular}{lccc}
\hline Parameters & Control (Healthy Dogs) $\mathrm{n}=15$ & Diarrhoeic $($ Infected) $\mathrm{n}=21$ & Diarrhoeic (Non-infected) $\mathrm{n}=15$ \\
\hline GPx $(\mu \mathrm{mol} / \mathrm{mg})$ & $64.9 \pm 1.47$ & $59.2 \pm 2.89$ & $61.4 \pm 0.93$ \\
SOD $(\mathrm{U} / \mathrm{mg})$ & $39.2 \pm 0.73$ & $32.1 \pm 1.14^{*}$ & $35.8 \pm 0.80$ \\
Catalase $(\mu \mathrm{mol} / \mathrm{mg})$ & $23.5 \pm 1.37$ & $20.6 \pm 0.89$ & $14.5 \pm 0.47^{* * *}$ \\
MDA $(\mu \mathrm{mol} / \mathrm{mg})$ & $1.3 \pm 0.05^{* *}$ & $2.9 \pm 0.11^{*}$ & $3.6 \pm 0.14^{* * *}$ \\
\hline
\end{tabular}

Mean \pm SEM. Means marked * are significantly different from control group while those marked $* *$ are significantly different from diarrhoeic (infected) group. 
Table 3: The mean electrolytes levels of CPV-2 diarrhoeic infected and diarrhoeic non-infected puppies

\begin{tabular}{lccc}
\hline Parameters & Control (Healthy Dogs) $\mathrm{n}=15$ & Diarrhoeic $($ Infected) $\mathrm{n}=21$ & Diarrhoeic (Non-infected) $\mathrm{n}=15$ \\
\hline $\mathrm{Na}^{+}(\mathrm{mEq} / \mathrm{L})$ & $124.6 \pm 1.37$ & $138.2 \pm 4.85$ & $112.1 \pm 8.21^{* *}$ \\
$\mathrm{~K}^{+}(\mathrm{mEq} / \mathrm{L})$ & $4.3 \pm 0.09^{* *}$ & $2.8 \pm 0.14^{*}$ & $2.9 \pm 0.32^{*}$ \\
$\mathrm{Cl}^{-}(\mathrm{mEq} / \mathrm{L})$ & $98.8 \pm 1.61$ & $102.3 \pm 5.86$ & $111.9 \pm 3.55$ \\
$\mathrm{HCO}_{3}-(\mathrm{Mmol} / \mathrm{L})$ & $22.1 \pm 0.55^{* *}$ & $27.7 \pm 0.59^{*}$ & $26.8 \pm 0.60^{*}$ \\
\hline
\end{tabular}

Mean \pm SEM. Means marked * are significantly different from control group while those marked $* *$ are significantly different from diarrhoeic (infected) group.

\section{Discussion}

Diarrhoea and vomiting are the most consistent clinical manifestations usually found in CPV-2 infections, although other nonspecific signs such as anorexia, lethargy, weakness, dehydration and fever may be observed (10-12). The significantly $(\mathrm{P}<0.05)$ lower haematological parameters (RBC counts, PCV and HB Concentrations) in the diarrhoeic CPV-2 infected group, could be attributed to haemorrhagic diarrhoea observed in the clinical cases and blood loss through the faeces, due to damage of the vascular epithelium of the intestine as the disease progresses $(23,24)$. Virus suppression of the bone marrow has been described to play a major role in the pathophysiology of canine parvovirus, with a marked decrease seen in myeloid, erythroid and megakaryocytic cells, which leads to decrease in the life span of red blood cells $(25,26)$.

In this study increased in leucocyte counts (Leucocytosis) was observed in the diarrhoeic infected group, which agrees with the works of Goddard et al (27) and Kalli et al (12) who did not observe significant leukopenia in CPV-2 infected dogs. The increased leucocytes counts might be due to the fact that most of the blood sample in the above cases might have been collected at the earlier stages of viremia rather than later stages when leucocytosis had already been developed due to secondary bacterial infection $(23,28)$. Greene and Appel (29) and Padro (30) in a similar study, reported that leukopenia is a consistent finding in CPV-2 infection in dogs. It is widely speculated that leucocytes counts can be used as a prognostic marker for dogs that are hospitalized or overtime in assessing dogs that have previously suffered parvoviral enteritis (9). The more severe the leukopenia the graver the prognosis in general, as leukopenia corresponds to sever clinical CPV-2 infection, while leucocytosis, however, tends to develop in the later stages of the disease associated with secondary bacterial infection markers, and generally indicates a more favourable prognosis $(27,31)$.

Antioxidant enzyme levels are sensitive of oxidative stress. Both increased and decreased levels have been reported in different diseases as a consequence of reactive oxygen species (ROS) production either by up-regulation of enzyme activity or utilization of the antioxidant enzymes to counter the ROS. In this present study, the mean SOD and
CAT activities were significantly low in diarrhoeic infected and diarrheic non-infected groups respectively. This result however, indicates that antioxidant depletion has been incriminated in the pathogenesis of many disease processes of animals and humans, including CPV-2 infection. The significantly higher malondialdehyde (MDA) observed in the diarrhoeic non-infected group, than diarrhoeic infected group, agrees with Panda et al (2) who observed a significant alteration in the MDA in dogs suffering from gastroenteritis irrespective of parvoviral enteritis.

The lower $\mathrm{K}^{+}$(hypokalaemia) level observed both in diarrhoeic infected and diarrhoeic non-infected groups compared to the control, may be due to anorexia, vomiting and diarrhoea which, contribute to depression and weakness and severity of infection $(8,32)$. This result also agrees with Panda et al (2) who observed no significant difference in the serum potassium level in gastroenteritis associated with CPV-2 and gastroenteritis not associated with CPV-2. The significantly lower $\mathrm{Na}^{+}$level was observed in the diarrhoeic non-infected group, compared to diarrhoeic infected group. This was similarly reported by Panda et al (2) who observed a significantly lower serum $\mathrm{Na}^{+}$level in gastroenteritis in dogs without canine parvovirus infection. Fluid loss with consequent dehydration, electrolyte losses (sodium, potassium, Bicarbonate, chloride), and even vascular collapse sometimes occur in humans and animals (33).

\section{Conclusion}

It was concluded from this study, that the haematological parameters (RBC counts, PCV and HB Concentrations) are likely to decrease in a CPV-2 infected dogs leading to anaemia. Generally, the level of oxidative stress and electrolyte alterations may not be affected or dependent on the aetiology or origin of infection (canine parvoviral enteritis) but on the severity of the infection.

\section{Acknowledgment}

I sincerely wish to acknowledge the laboratory technologist Dr. S. N. Ijioma and all the clinicians and clinics that helped us during the sample collection. 


\section{References}

1. Carmichael LE, An annotated historical account of canine parvovirus. J Vet Med. 2005;52:303-311. Doi: 10.1111/j.1439-0450.2005.00868.x

2. Panda D, Patra RC, Nandi D, Swarup D. Oxidative stress indices in gastroenteritis in dogs with canine parvoviral infection. Res Vet Sci. 2009;86:36-42. Doi: 10.1016/j.rvsc.2008.05.008

3. Castro TX, Miranda SC, Labarthe NV, Silva LE, Cubel Garcia RCN. Clinical and epidemiological aspects of canine parvovirus (CPV) enteritis in the State of Rio de Janeiro: 1995-2004. Arq Brasileiro de Med Vet Zoo. 2007;59(2):333-339. Doi: 10.1590/s010209352007000200010

4. Gombac M, Tadic M, Svara T, Pogaenik M. Canine Parvovirus: A Review. Inter J Sci Appl Res. 2017;2(2):74-95. Doi: 10.1036/10978542.757249

5. Goddard A, Leisewitz AL. Canine Parvovirus. Vet Clin Small Anim Pract. 2010;40:1041-1053. Doi: 10.1016/b978-1-56053-421-1.50093-4

6. Duffy A, Dow S, Ogilvie G, Rao S, Hackett T. Hematologic improvement in dogs with parvovirus infection treated with recombinant canine granulocyte-colony stimulating factor. $\mathrm{J}$ Vet Pharmacol Theriogenol. 2010;33(4):352-356. Doi: 10.1111/j.13652885.2009.01153.x

7. Sykes JE. Canine parvovirus infections and other viral enteritis. In: Sykes JE editor. Canine and Feline Infectious Diseases. $1^{\text {st }}$ ed. St Louis: Elsevier; 2014. 141-151 p. doi: 10.1016/b978-1-4377-0795-3.00014-4

8. Schoeman JP. State of the Art: Biomarkers in parvoviral enteritis. World Small Animal Veterinary World Congress Proceedings; 2013.

9. Mylonakis ME, Kali I, Rallis TS. Canine parvoviral enteritis: Update on the clinical diagnosis, treatment, and prevention. Vet Med Res Rep. 2016;7:91-100. Doi: 10.2147/vmrr.s80971

10. Houston DM, Ribble CS, Head LL. Risk factors associated with parvovirus enteritis in dogs: 283 cases (1982-1991). J Am Vet Med Ass. 1996;208:542-546. Doi: 10.4314/ari.v2i3.40870

11. McCaw D, Hoskins JD. Canine Viral enteritis. In: Green CE editor. Infectious disease of the dog and cat. $4^{\text {th }}$ ed. St Louis: Saunders; 2006. 63-73 p.

12. Kalli I, Leontides LS, Mylonakis ME, Adamama K, Koutinas AF. Factors affecting the occurrence duration of hospitalization and final outcome in Canine parvovirus infection. Res Vet Sci. 2010;89(2):174178. Doi: 10.1016/j.rvsc.2010.02.013

13. Turk J, Miller M, Brown T. Coliform septicemia and pulmonary disease associated with canine parvoviral enteritis: 88 cases (1987-1988). J Am Vet Med Ass. 1990;196:771-773. PMID: 2155191

14. Otto CM, Drobatz KJ, Soter C. Endotoxemia and tumour necrosis factor activity in dogs with naturally occurring parvoviral enteritis. $\mathrm{J}$ Vet Inter Med. 1997;11(2):65-70. Doi: 10.1111/j.19391676.1997.tb00075.x

15. Torres MA, Jones JA, Danji JL. Reactive oxygen species signalling in response to pathogens. Plant Physiol. 2006; 141(2):373-378. Doi: 10.1002/9780470988565.ch7.

16. Eze JI, Anene BM, Chukwu CC. Determination of serum and organ malondialdehyde (MDA) concentration, a lipid peroxidation index, in Trypanosoma brucei infected rat. Comp Clin Pathol. 2008;17(2):67-72. Doi: 10.1007/s00580-008-0722-6.

17. Manisha N, Hasan W, Rajak R, Jat D. Oxidative stress and antioxidants: an overview. Inter J Advan Res Rev. 2017;2(9):110-119. Doi: $10.5772 / 34134$.
18. Esfandiari J, Klingeborn B. A comparative study of a new rapid and one-step test for the detection of parvovirus in faeces from dogs, cats and mink. J Vet Med B Infect Dis Vet Pub Heal. 2000;47:145-153. Doi: 10.1046/j.1439-0450.2000.00328.x

19. Moron MS, Depierre JW, Mannervik B. Levels of glutathione, glutathione reductase and glutathione s-transferase activities in rat lung and liver. Biochem Biophysica Acta. 1979;582:67-78. doi: 10.1016/0304-4165(79)90289-7. Doi: 10.1016/0304-4165(79)90289-7

20. Markland S, Markland G. Involvement of Superoxide anion radical in the anti-oxidation of pyrogallol and convenient assay for superoxide dismutase. Euro J Biochem. 1974;469-474. Doi: 10.1111/j.14321033.1974.tb03714.x

21. Sinha AK. Colorimetric Assay of Catalase. Analy Biochem. 1972;47:389-394. doi: 10.1016/0003-2697(72)90132-7. Doi: 10.1016/0003-2697(72)90132-7

22. Wallin B, Rosengren B, Shertzer HG, Camejo, G. Lipoprotein oxidation and measurement of thiobarbituric acid reacting substances formation in a single microtiter plate: Its use for evaluation of antioxidants. Analy Biochem. 1993;208:10-15. Doi: 10.1006/abio.1993.1002

23. Biswas S, Das P, Ghosh SK, Pradhan NR. Detection of canine parvovirus (CPV) DNA by polymerase chain reaction assay and its prevalence in dogs in and around Kolkata, West Bengal. Indian J Anim Sci. 2006;76(4):324-325.

24. Wazir VS, Gupta SK, Bhardwaj RK, Taku AK, Summers BA. Clinichaematological alterations in CPV. In Proceedings of $29^{\text {th }}$ ISVM Convention and National Symposium on "Recent Developments in Diagnostics and Therapeutics Including Applications of NanoTechnology in Veterinary Medicine" 17 -19 February 2011.

25. Meyer DJ, Harvey JW. Veterinary Laboratory Medicine: Interpretation and diagnosis. $2^{\text {nd }}$ ed. New York: Saunders, 1998: 43-82. Doi: 10.1111/j.1939-1676.1992.tb00356.x

26. Ezeibe MCO, Udegbunam RI. Haematology of dogs infected with canine distemper virus. Sokoto J Vet Sci. 2008;7(2):31-33.

27. Goddard A, Leisewitz AL, Christopher MM, Duncan NM, Becker PL. Prognostic usefulness of blood leukocyte changes in canine parvoviral enteritis. J Vet Inter Med. 2008;22(2):309-316. Doi: 10.1111/j.19391676.2008.0073.x

28. Dash S, Das MR, Sathapathy S, Patra RC, Senapati SK, Jena GR. Haematological, Serum Biochemical Alterations and Efficacy of different therapeutic regimens in Haemorrhagic Gastroenteritis with special reference to Canine Parvovirus infection. Glob J Biosci Biotechnol. 2017;6(2):267-271. Doi: 10.5958/0973970x.2016.00062.6

29. Greene CE, Appel MJ. Canine Distemper. In: Greene CE editor. Infectious diseases of the dogs and cats. $3^{\text {rd }}$ ed. New York: Elsevier; 2006.

30. Pardo IPR. Phylogenetic characterization of canine distemper virus detection in naturally infected North American dogs. [PhD dissertation]. Missouri: Graduate school of University of MissouriColumbia, Missouri, USA; 2006.

31. Simpson E. Small intestinal disease, manual of feline and canine Gastroenterology. Euro J Pub. 1996;11(2):12-20.

32. Li R, Humm KR. Canine parvovirus infection. In: Silverstein DC, Hoper K editors. Small Animal Critical Care Medicine. $2^{\text {nd }}$ ed. St Louis: Elsevier; 2015. 509-513 p. doi: 10.1016/b978-1-4160-2591-7.10112-2

33. Anigilaje EA. Management of Diarrhoeal Dehydration in Childhood: A Review for Clinicians in Developing Countries. Frontiers in Ped. 2018;6:1-19. Doi: 10.3389/fped.2018.00028. 